for the $3,000 \mathrm{~m}$, water depths. Most of the essential features of the dynamic isobars are confirmed by the pattern of near surface isotherms.

Comparison of Figs. $1 a$ and $1 b$ which have similar horizontal scales shows that over the Agulhas Plateau both current patterns exhibit an equatorward tendency, which immediately downstream of the Plateau gives way to a sharp poleward and then equatorward deflection. The computed pattern has a phase lag which can be theoretically ascribed to the simplified form of bathymetry used. Its arnplitude is, however, quite unrealistically large; although relatively large amplitudes are to be expected because the width of the Agulhas Plateau approaches a half wavelength.

Further downstream, the computed flow again deflects sharply poleward and then equatorward. The large deflection here (it is actually infinite) is caused by the increase in depth at about one wavelength distant from the Plateau. There are unfortunately no comparable hydrographic data available for this region.

Finally, over the western slope of the Madagascar Ridge both flow patterns show an equatorward deflection.

Noteworthy features indicated by the dynamic isobars are the northward branching currents, which seem to separate from the main Agulhas Return Current near the maximum equatorward deflections of the meanders. These branching currents are particularly conspicuous over the Madagascar and Indian Ridges and agree well with surface current charts based on ships' drifts ${ }^{10}$. Lacombe ${ }^{11}$ and Le Pichon ${ }^{2}$ have noted this tendency.

It seems that in the South West Indian Ocean there is a gyre on the west side which has an eastern limit in the region of $60^{\circ}-70^{\circ} \mathrm{E}$. In this vicinity, the zonal flow of the Agulhas Return Current appears from the dynamic topography to be much diminished.

Although the limitations of the dynamic topography method and the severe restrictions imposed on the mathematical model require caution in interpreting the flow patterns, it is clear from this comparative study that there are quite striking similarities between the baroclinic and barotropic modes in the Agulhas Return Flow. It is concluded that the bottom topography may well be a contributory influence on the direction of flow of this current and could account for the deflections near the Agulhas Plateau. The Agulhas Return Current provides a good opportunity for these conclusions to be tested more rigorously.

I thank Mr J. N. Marshall for very useful discussions on the computations and the Division of Sea Fisheries for making RSA Africana II data available.

T. F. W. HARRIS

Department of Oceanography,

University of Cape Town.

Received May 6, 1970.

${ }^{1}$ Dietrich, G., Veroff. des. Inst. fur Meereskunde, 27,1 (1935).

"Le Pichon, X., J. Geophys. Res., 85, 12, 4061 (1960).

${ }^{3}$ Darbyshire, J., Deep Sea Res., 11, 781 (1964).

${ }^{4}$ Porter, G. H., and Rattray, jun., M., Deut. Hydr. Zeit., 17, 4, 164 (1964).

- Simpson, E. S. W., and Forder, E., Chart $123 A$ (third ed.) (University of Cape Town, 1969).

'Shipley, A. M., and Zoutendyk, P., Univ. Cape Toun, Data Report 2 (1964).

"Orren, M. J., Invest. Rep. Sea Fish. S. Afr., 45 (1963).

${ }^{5}$ S.A. Division of Sea Fisheries, Manuscript data Africana II cruise, July 1962 .

${ }^{9}$ Woods Hole Oceanographic Institution, Anton Bruun, Cruise 6 (1965).

10 Meteorological Office, Met. Office 772 (HM Stationery Office, 1966).

"1 Tehernia, P., Le Floch, J., Lacombe, H., Bull. d' Information du Comité

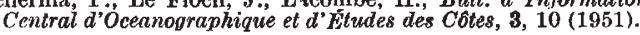

\section{Effect of Adhesive Tape on the Velocity Profile of Water}

I REPORT here an interesting discovery, made while investigating velocity profiles close to a solid boundary. The experiments were carried out in a 5 inch channel of square section filled with water to a depth of 4.5 inches. Total head and static head tubes constructed of hypodermic tubing $(0.020$ inches outside diameter; 0.010 inches inside diameter) were used to measure the head by mean of a $0-5$ inch water gauge transducer of differential transformer type. Experiments were performed in a region of fully developed turbulent flow in order to discover the effect on the velocity profile of roughening tho channel bed by sticking sand grains of various known dimensions to it by means of double-sided 'Scotch-Tape'. 